\title{
INFLUÊNCIA DA GRAMÁTICA FILOSÓFICA NO CONCEITO DE VERBO EM GRAMÁTICAS BRASILEIRAS
}

\section{THE INFLUENCE OF THE PHILOSOPHICAL GRAMMAR ON THE VERB CONCEPT OF BRAZILIAN GRAMMARS}

\author{
Mairus Prete* \\ Instituto Federal do Paraná, Jacarezinho, PR, Brasil
}

\begin{abstract}
Resumo: Nosso objetivo no presente artigo é analisar a influência da gramática filosófica no conceito de verbo presente em gramáticas publicadas em dois momentos da gramaticografia brasileira: o final do século XIX e o iníio do século XX; o final do século XX e o iníio do século XXI. Para isso, descrevemos os critérios distintivos do conceito de verbo em gramáticas filosóficas, como a de Jerônimo Soares Barbosa, e depois comparamos com os conceitos presentes nas gramáticas que selecionamos para nosso corpus. Esse procedimento nos levou a constatar que os conceitos de verbo das gramáticas selecionadas apresentam critérios distintivos semelhantes ao da gramática filosófica, fato que relativiza a ideia de que esta seja uma tradição totalmente superada pelas gramáticas publicadas na transiçãoo do século XIX para o XX, ou uma tradiç,ão irrelevante em gramáticas publicadas na transição do século XX para o XXI. Realizamos esta pesquisa com base nos pressupostos da História das Ideias Lingúisticas (AUROUX, 2009), corrente para a qual a acumulação de conhecimento é fundamental seu desenvolvimento na longa duração do tempo.
\end{abstract}

Palavras-chave: História das ideias linguísticas; gramáticas brasileiras; conceito de verbo; criteríios distintivos; acumulação do conhecimento.

\begin{abstract}
Our aim in this paper is to analyze the influence of the philosophical grammar on verb concept present in grammars published in two different moments of the Brazilian gramaticography: the end of the $19^{\text {th }}$ century and the beginning of the $20^{\text {th }}$ century; the end of the $20^{\mathrm{t}}$ century and the beginning of the $2 \mathrm{1}^{\mathrm{s}}$ century. For this, we described the distinctive criteria of the verb concept in the philosophical grammars, as the one by Jerônimo Soares Barbosa, and later on we compared to the present concepts in the grammars we selected to our corpus. Such procedure led us to verify that the concepts of verb from the selected grammars have distinctive criteria similar to the ones from the philosophical grammar, fact that put into perspective the idea that this is a tradition totally overcome by the grammars published in the transition of the $19^{\text {th }}$ to the $20^{\text {th }}$ century, or an irrelevant grammatical tradition in the transition of the $20^{\mathrm{th}}$ century to the $27^{\text {ts }}$. We accomplished this research based on the postulations of the History of the Linguistic Ideas (AUROUX 2009), in which the growth of knowledge is fundamental for its development in a long-term perspective.
\end{abstract}

Keywords: History of the Linguistic Ideas; Brazilian Grammars; Verb Concept; Distinctive Criteria; Accumulation of Knowledge

* Instituto Federal do Paraná - IFPR, Jacarezinho, PR, Brasil; Universidade de São Paulo - USP, São Paulo, SP, Brasil; mairus.prete@ifpr.edu.br

hittp://dx.doi.org/10.11606/issn.2236-4242.v32ilp175-193

Todo conteúdo da Linha D'Água está sob Licença Creative Commons Attribution-NonCommercial 4.0 International License 
Linha D'Água (Online), São Paulo, v. 32, n. 1, p. 175-193, jan.-abril 2019

\section{Introdução}

Auroux (2006) apresenta-nos uma metáfora bastante curiosa para ilustrar como a acumulação é importante para que o conhecimento se desenvolva. Para o pesquisador, uma locomotiva a vapor, embora simbolize uma revolução nos meios de locomoção, carrega consigo vestígios de uma das primeiras soluções inventadas pela humanidade para se locomover: as rodas. Nessas rodas, ainda que sejam feitas de um material totalmente distinto de suas ancestrais, é possível encontrar os mesmos princípios de aplicação e transformação de força linear aplicados em sua versão mais rudimentar, inventada muito antes de uma locomotiva a vapor ser uma possibilidade.

A ideia por trás dessa metáfora é a de que não existe o conhecimento inédito sem outro, anterior, que o sustente, mesmo que este passe despercebido devido à sua trivialidade. Não temos dúvidas de que isso também ocorra com o desenvolvimento das ideias linguísticas na longa duração do tempo, principalmente com as presentes nas gramáticas, objetos técnicos por natureza (AUROUX, 2006). A acumulação de conhecimento é a condição sine qua non para o desenvolvimento das ideias presentes nas gramaticais ocidentais. Nas palavras de Auroux, "lobjet technique est là devant nous; nous le préservons, le reconstruisons, le démontons, en prenons des morceaux pour les intégrer à de nouveaux objets." (AUROUX, 2009, p. 12).

Neste artigo, nosso objetivo é trazer à luz essa acumulação de conhecimento na elaboração do conceito de verbo, a partir da descrição dos critérios que os autores de gramática utilizaram nessa elaboração. Nossas análises visam a testar a hipótese de que a tradição da gramática filosófica ${ }^{2}$ ainda exerça algum tipo de influência em gramáticas brasileiras elaboradas entre o final século XIX e início do século XX; e em gramáticas elaboradas entre o final do século XX e o início do século XXI. Suspeitamos de que a tradição da gramática filosófica possa ser observada nesses dois momentos da gramaticografia brasileira, ambos reconhecidos

1 Tradução livre: os objetos técnicos estão a nossa frente; nós os protegemos, os reconstruímos, os desmontamos em peças menores para integrar a novos objetos.

2 Entendemos como tradição filosófica as gramáticas que foram redigidas sob a influência da Grammaire générale et raisonnée contenant les fondemens de l'art de parler, expliqués d'une manière claire et naturelle, publicada em 1660, por Antoine Arnauld e Claude Lancelot.

PRETE, M. Influência da gramática filosófica no conceito de verbo em gramáticas brasileiras 
Linha D'Água (Online), São Paulo, v. 32, n. 1, p. 175-193, jan.-abril 2019

por sua tentativa de romper com o passado (Cf. CAVALIERE, 2014; CASSEBGALVÃO \& NEVES, 2014).

Compõem nosso corpus de análise as seguintes obras publicadas entre o final do século XIX e o início do século XX: a primeira e a segunda edição da Grammatica portugueza, de Júlio Ribeiro (1881 e 1885, respectivamente); a Grammatica portugueza: curso superior, de João Ribeiro (1887); a Grammatica expositiva, de Eduardo Carlos Pereira (1907); e a Grammatica descriptiva, de Maximino Maciel (1914). Também compõem nosso corpus as seguintes gramáticas publicadas entre o final do século XX e o início do século XXI: a Gramática de usos do português, de Maria Helena de Moura Neves (1999); a Gramática do português brasileiro, de Mário Perini (2010); e Nova gramática do Português brasileiro, de Ataliba de Castilho (2010).

\section{Tradições da gramaticografia brasileira}

Escolhemos essas gramáticas porque elas compõem uma amostra significativa dos dois momentos que selecionamos para análise. Sabemos que é vasto o número de trabalhos que visam a fornecer um panorama interpretativo da gramaticografia brasileira por meio de periodizações. Podemos citar as periodizações de Nascentes (2003 [1939]), de Elias (1963) e de Cavaliere (2001), entre outras, que estabelecem fases para gramaticografia brasileira. E podemos citar estudos mais recentes, como o de Parreira (2011) e o Polachini (2015a), por exemplo, que revisam as periodizações anteriores a partir de análises mais verticalizadas das obras.

É comum em todos esses estudos a visão de que a virada do século XIX para o XX foi um período em que a gramaticografia brasileira passou por uma transição entre tradição da gramática filosófica, vinculada à Gramática de Port-Royal, para a tradição da gramática histórico-comparativa, fundamentada em nomes como de Franz Bopp, Max Müller e Whitney (Cf. FÁVERO \& MOLINA, 1996, 2006). As periodizações divergem no modo como essa transição ocorreu: se de modo parcial, como Parreira (2011) e Polachini (2015a) defendem; ou total, como defendem Nascentes (1939), Elias (1963), Cavaliere (2001). O fato é que as gramáticas publicadas nesse momento são, de alguma forma, consideradas obras particularmente diferentes das que surgiram durante a égide da tradição da gramática filosófica.

PRETE, M. Influência da gramática filosófica no conceito de verbo em gramáticas brasileiras

Todo conteúdo da Linha D'Água está sob Licença Creative Commons Attribution-NonCommercial 4.0 International License 
Linha D'Água (Online), São Paulo, v. 32, n. 1, p. 175-193, jan.-abril 2019

Nossa escolha pelas duas primeiras edições Grammatica portugueza, de Júlio Ribeiro (1881 e 1885), deve-se ao fato de que a primeira edição, de 1881, é apontada pela periodização de Cavaliere (2001), por exemplo, como a pioneira na adoção do método histórico-comparativo no Brasil; e por Vital Neto (2010) como a responsável por uma mudança epistemológica na forma de abordagem da língua portuguesa falada no Brasil. Também utilizamos a sua segunda edição, de 1885, porque encontramos nela uma mudança relevante no conceito de verbo desenvolvido por Júlio Ribeiro, fato que não poderíamos simplesmente ignorar.

Escolhemos também a Grammatica portugueza: curso superior, de João Ribeiro (1887), porque, além de também ser mencionada pelas periodizações como obra importante nesse cenário de transição, é considerada por Câmara (2004 [1969]) como a obra mais importante na transição entre as tradições da gramática filosófica para a da histórico-comparativa. E escolhemos, por fim, a Grammatica expositiva, de Eduardo Carlos Pereira (1907), e a Grammatica descriptiva, de Maximino Maciel (1914), porque esta é considerada uma obra que se apropriou da tradição histórico-comparativa de forma mais consistente, enquanto aquela é a que atingiu a maior repercussão entre as gramáticas redigidas dentro dessa tradição (Cf. FÁVERO \& MOLINA, 2006; CAVALIERE, 2014).

As outras três gramáticas que selecionamos para representar a transição entre o final do século XX e o início do século XXI - a Gramática de usos do português, de Maria Helena de Moura Neves (1999); a Gramática do português brasileiro, de Mário Perini (2010) e Nova gramática do Português brasileiro, de Ataliba de Castilho (2010) - estão situadas em um contexto que também é considerado por estudiosos como um cenário particular. Mota et al. (2017), por exemplo, aponta que essas obras "promovem movimentos de ruptura ao que já está posto pelos manuais anteriores” (MOTA, 2017, p. 556). E Rangel (2013), por sua vez, defende que essa mudança ocorre porque a Linguística passou a exercer influência sobre essas gramáticas. Ou seja: são gramáticas publicadas a partir de uma suposta fronteira na gramaticografia brasileira, assim como as demais selecionadas para representar o final do século XIX e início do século XX.

Geralmente, essas oito gramáticas têm sido interpretadas como obras em que refratam tradições passadas, fato do qual suspeitamos. Mesmo que mudanças 
Linha D'Água (Online), São Paulo, v. 32, n. 1, p. 175-193, jan.-abril 2019

ocorram, não acreditamos que isso deva ser interpretado como momentos de definitivas rupturas com tradições anteriores, pois é equivocado afirmar que essas obras tenham se desprendido totalmente delas:

Esse instrumento empírico, "gramática", tal como o conhecemos desde a tradição greco-latina, é um objeto técnico, cultural, que vai se modificando ao longo da história, embora tenha mantido uma estrutura que permite seu reconhecimento como tal. [...] Observa-se, todavia, que, no decurso da história, a apresentação e descrição das categorias linguísticas foram modificadas, por acréscimo, diminuição, ou hierarquização, por alteração da ordem de exposição do conteúdo ou pela redefinição de conceitos, pela inclusão de novas teorias para análise da língua e, pelo que se vê em obras do século XXI, esse escopo foi ampliado para a linguagem, o discurso e o texto, em razão da evolução da ciência e da filosofia. Não obstante, esse modelo teórico, que serviu para gramatizar as línguas modernas ocidentais, permanece "relativamente estável" e, ainda hoje, produtivo. (LEITE, 2014, p. 116).

Ainda que ao longo do tempo as obras gramaticais passem por modificações, a autora esclarece que existe nelas certo grau de estabilidade que nos permite o reconhecimento dessas obras como gramáticas. Há elementos que, embora possam ser modificados ou reestruturados, permanecem presentes, o que faz desta permanência vestígio inconteste de que as gramáticas são possíveis apenas se considerados os conhecimentos acumulados desde as primeiras obras, ainda redigidas na Grécia antiga. É por isso que esperamos identificar elementos característicos da tradição da gramática filosófica nas obras que selecionamos: essa tradição imprimiu seus elementos no tempo, assim como o fez a tradição da gramática latina.

\section{0 conceito de verbo e critérios para sua distinção}

Escolhemos o conceito de verbo como ponto de análise por se tratar de uma categoria gramatical que se encontra em todas gramáticas redigidas no ocidente, desde as primeiras gramáticas gregas. Também nos motivou a escolher essa categoria o fato de ela ser reconhecidamente importante na análise linguística, tanto no que diz respeito à sintaxe, quanto no que diz respeito à semântica e à pragmática, o que tem motivado inúmeros trabalhos a seu respeito nos mais variados campos de pesquisas.

PRETE, M. Influência da gramática filosófica no conceito de verbo em gramáticas brasileiras 
Auroux (2009) explica que as categorias gramaticais, ao longo da história, não sofreram grandes modificações em relação àquelas que apareceram nas primeiras gramáticas latinas, na medida em que o nome, o verbo, o particípio, o artigo, o pronome, a preposição, o advérbio e a conjunção são categorias gramaticais que integram a Tekhnê, de Dionísio de Trácia, ainda no século II a.C., e, de modo geral, estão presentes até os dias de hoje em qualquer gramática. São elementos das gramáticas que possuem relativa estabilidade e, por isso, são bons meios para observamos a acumulação do conhecimento.

Auroux (2009) esclarece, contudo, que, mesmo diante dessa estabilidade, os critérios para definir as "propriedades distintivas que permitem a classificação" (2009, p. 105) se modificaram ao longo do tempo, pois, ainda que uma dada categoria esteja em todas as gramáticas redigidas a partir da tradição ocidental, as propriedades distintivas que servem de balizas para a sua distinção se alteram. Por esse motivo, entendemos que essas propriedades sejam um aspecto valioso para comprovação de nossa hipótese: se as propriedades que distinguem as classes gramaticais podem se modificar, sua permanência em gramáticas de diferentes épocas e tradição são forte parâmetro para identificar a acumulação de conhecimento.

Auroux (2009) aponta quatro grandes critérios para fundamentar essas propriedades distintivas: (a) o critério morfológico; (b) os critérios semânticos; (c) os critérios funcionais; e (d) os critérios metalinguísticos.

Tabela 1: Critérios para distinção de categorias gramaticais, segundo Auroux (2009)

(a) Morfológico

\begin{tabular}{|c|c|c|c|}
\hline \multirow{11}{*}{ Critérios } & \multirow{3}{*}{ (b) Semântico } & \multicolumn{2}{|l|}{ (b1) Psicológico } \\
\hline & & \multicolumn{2}{|l|}{ (b2) Ontológico } \\
\hline & & \multicolumn{2}{|l|}{ (b3) Semiológico } \\
\hline & \multirow{4}{*}{ (c) Funcional } & \multicolumn{2}{|l|}{ (c1) Lógico } \\
\hline & & \multicolumn{2}{|l|}{ (c2) Sintático } \\
\hline & & \multirow{2}{*}{ (c3) Distribucional } & - Paradigmático \\
\hline & & & - Sintagmático \\
\hline & \multicolumn{3}{|c|}{ (d1) Comunicacional } \\
\hline & \multirow{3}{*}{ (d) Metalinguístico } & \multirow{3}{*}{ (d2) Metagramatical } & - Parafrásico \\
\hline & & & - Etimológico \\
\hline & & & - Didático \\
\hline
\end{tabular}

PRETE, M. Influência da gramática filosófica no conceito de verbo em gramáticas brasileiras 
O critério morfológico é a caracterização dos fenômenos linguísticos "a partir de sua estrutura e variações” (AUROUX, 2009, p. 105). O critério semântico, por sua vez, consiste em "toda propriedade que caracteriza os fenômenos linguísticos a partir da sua(s) relação(ões) com elementos não-linguísticos (AUROUX, 2009, p. 105). O autor divide esse critério em: (b1) psicológico: propriedade de representar faculdades do espírito; (b2) ontológico: propriedade de representar estruturas do mundo; e (b3) semiológico: propriedade de se contrapor a outro signo.

$\mathrm{O}$ critério funcional está relacionado à distinção de uma categoria a partir de "sua inserção em uma unidade superior quer esta seja nomeada quer não" (AUROUX, 2009, p. 107). Esse critério também é dividido por Auroux (2009) em: (c1) lógico: quando faz menção à vocabulários da lógica clássica; (c2) sintático: quando há relação do elemento com uma cadeia linguística maior; e (c3) distribucional: quando o critério é a propriedade de ser substituído no eixo paradigmático ou de concorrência no eixo sintagmático.

O critério metalinguístico, por fim, diz respeito à menção do "próprio enunciado linguístico" (AUROUX, 2009, p. 108). É dividido em (d1) comunicacional: quando há referência à situação de interlocução; e (d2) metagramatical: quando a metalinguagem gramatical é utilizada como propriedade distintiva. A propriedade metagramatical pode ser parafrásica (quando o conceito é obtido via paráfrase), etimológica (quando o conceito é obtido via etimologia) ou didática (quando o conceito é obtido da própria atividade do gramático).

Em estudo sobre as classes de palavras na tradição filosófica, Auroux (1988) aponta que os autores de gramáticas dessas gramáticas têm predileção pelos critérios semântico-ontológico (b2); semântico-semiológico (b3); e funcional-lógico (c1) para distinção das classes de palavras, embora outros critérios também possam ser utilizados. Nesse sentido, é interessante notarmos que Auroux (2009) até menciona gramáticas dessa tradição ao apresentar a definição dos critérios semiológico e lógico:

B.3. Semiológico: a propriedade concerne ao elemento definido enquanto signo de uma espécie ou de outra. Exemplos: signo completo vs. signo incompleto; fundando-se na função do signo: nomear vs. exprimir vs, pronunciar (são critérios de Condillac: "Não é preciso senão substantivos para nomear todos os objetos de que podemos falar: só é preciso adjetivos para exprimir todas as qualidades; é

PRETE, M. Influência da gramática filosófica no conceito de verbo em gramáticas brasileiras 
preciso preposições para indicar as suas relações: enfim, é preciso apenas o verbo ser para pronunciar todos os nossos julgamentos"); ou ainda: palavra conotativa vs. palavra denotativa (Port-Royal).

[...]

C.I. Lógica: a propriedade em questão se relaciona com os termos teóricos da disciplina nomeada lógica: sujeito, cópula, predicado, atributo etc. Exemplos conter a cópula vs. poder ser sujeito (definição da oposição verbo-nominal); “(o verbo) uma palavra cujo principal uso é significar a afirmação" (Port-Royal); o adjetivo desenvolve ou determina a significação do nome (Condillac). (AUROUX, 2009 107-108).

Isso ocorre porque o critério semântico-semiológico (b3) e o funcional-lógico (c1) correspondem a importantes aspectos teóricos da tradição da gramática filosófica. Para essa tradição, as operações do pensamento - conceber, jugar e raciocinar - são representadas pela linguagem. Conceber é compreender as coisas no mundo, julgar é afirmar algo sobre aquilo que é concebido, e racionar, por fim, é obter um terceiro julgamento a partir de outros dois anteriores (Cf. COLOMBAT, FOURNIER e PUECH, 2017). O verbo, nesse contexto teórico, torna-se elemento central, visto que cabe a ele a função de atar duas ideias para construção do julgamento: critério funcional-lógico(c1); e a função de expressá-lo: critério semântico-semiológico (b3). É justamente esse conceito de verbo - obtido a partir desses critérios - que estabelece a particularidade conceitual da tradição filosófica:

"Tal quadro torna-se aquele no qual os gramáticos põem os problemas relativos à análise das relações em torno do verbo e no qual se passa progressivamente da perspectiva essencialmente morfológica, que subentende a análise fundada sobre os casos herdados da gramática latina, para uma análise das funções, aquela supõe a passagem para outro plano de análise: aquele das relações (de solidariedade, de dependência...) entre constituintes, em termos formas e/ou semânticos. (COLOMBAT, FOURNIER \& PUECH, 2017, p. 176-177).

A adoção dessa perspectiva na conceituação de verbo pode ser facilmente notada na Grammatica philosofica da linguia portugueza, de Jerônimo Soares Barbosa 
Linha D'Água (Online), São Paulo, v. 32, n. 1, p. 175-193, jan.-abril 2019

$(1871 \text { [1822] })^{3}$, obra notadamente relacionada à tradição da gramática filosófica (FÁVERO, 1996). Observamos em seu conceito um bom exemplo do uso do critério semântico-semiológico (b3) e do funcional-lógico (c1), assim como da mudança da perspectiva morfológica, característica da tradição gramatical latina, para relacional, característica da tradição filosófica.

O verbo, «è uma parte conjunctiva do discurso, a qual serve para atar o attributo da proposição com o seu sujeito debaixo de todas suas relações pessoaes e numeraes, enunciando por differentes modos a coexistência e identidade de um com outro, por ordem aos differentes tempos e maneiras de existir.» (BARBOSA, 1871 [1822], p. 132).

Observamos, nesse excerto, o uso do critério semântico-semiológico (b3) e o do funcional-lógico (c1) na elaboração de seu conceito. A função de atar o atributo da proposição com o seu sujeito remete à disciplina filosófica da lógica, enquanto a ideia de enunciar a identidade de um com outro remete diretamente à função do signo. É importante ressaltar que é essa gramática que vai servir de alvo da retórica revolucionária contra a metafísica que acontece entre as gramáticas da virada do XIX para o XX. A Grammatica philosofica da linguia portugueza, de Jerônimo Soares, é explicitamente rechaçada por Júlio Ribeiro, por exemplo (Cf. POLACHINI, 2018).

\section{0 conceito de verbo em gramáticas brasileiras e sua distinção}

A primeira edição da Grammatica portugueza, de Júlio Ribeiro, publicada em 1881, apresenta o seguinte conceito para verbo: "161. Verbo é uma palavra que exprime a existência de uma relação entre duas ideias" (RIBEIRO, 1881, p. 61). Notamos que, nesse conceito de verbo, o autor atribui ao verbo a função de "exprimir" algo, o que revela o uso do critério semântico-semiológico (b3) para distinção de verbo, pois Júlio Ribeiro (1881) se pauta na função do signo para estabelecer seu traço distintivo. Ademais, a função de exprimir remete à expressão da "relação entre duas ideias", o que nos sugere que Júlio Ribeiro também utilizou o critério

3 Utilizamos a quinta edição por não conseguirmos acesso à primeira.

PRETE, M. Influência da gramática filosófica no conceito de verbo em gramáticas brasileiras 
Linha D'Água (Online), São Paulo, v. 32, n. 1, p. 175-193, jan.-abril 2019

funcional-lógico (c1), uma vez que cabe ao verbo a função de estabelecer a relação entre duas ideias, que são o sujeito e o predicado.

O uso do critério semântico-semiológico (b3) e o do critério funcional-lógico (c1) no conceito de verbo presente na primeira edição da Grammatica portugueza, de Júlio Ribeiro (1881), evidencia uma influência inegável da tradição da gramática filosófica. Além do conceito de verbo, a primeira edição da Grammatica portugueza, de Júlio Ribeiro (1881), contém um longo ensaio após o conceito de verbo, em que o autor discorre acerca do seu caráter distintivo.

Júlio Ribeiro inicia esse ensaio dizendo que "desde a mais remota antiguidade até hoje os grammaticos se não têm podido entender a respeito do kharacter essencial e distinctivo do verbo." (RIBEIRO, 1881, p. 61). Essa sua constatação o leva a discutir os conceitos de Aristóteles, de Port-Royal e do que chama de "gramáticos orientais", para defender o conceito que adotou com base em Whitney: "segue-se que é boa a definição de W.D. Whitney «Verbo é a palavra que diz ou declara»." (RIBEIRO, 1881, p. 66). Whitney, como se sabe, é um expoente da gramática histórico-comparativa, no entanto sua definição também é obtida por meio do caráter semântico-semiológico (b3): o verbo "diz" ou "declara".

$\mathrm{Na}$ segunda edição da Grammatica portugueza, publicada em 1885 por Júlio Ribeiro, essa problemática do verbo é simplificada. O ensaio em que Júlio Ribeiro discute o conceito de verbo é suprimido e outra definição é apresentada, claramente inspirada em Whitney: "158. Verbo é uma palavra que enuncia, diz ou declara alguma cousa. O verbo implica sempre uma asserção ou predicação" (RIBEIRO, 1885, p. 73). Mesmo que a segunda edição seja mais enfática na adoção do método histórico-comparativo, constatamos que Júlio Ribeiro (1885) ainda utiliza o caráter semântico-semiológico (b3) em seu conceito, visto que continua o conceituando como "uma palavra que enuncia, diz ou declara".

Neste conceito, a distinção por meio da função do signo é evidente, do mesmo modo como na primeira edição o era. No entanto, notamos que a troca da "relação entre duas ideias" por "implica sempre uma asserção ou predicação" aparenta uma tentativa de Júlio Ribeiro (1885) de afastar-se das concepções da tradição filosófica. Essa mudança, sem dúvida, oculta nomenclatura sugestiva dessa tradição "relação entre duas ideias”, mas não significa o abandono do caráter funcional-lógico (c1), 
Linha D'Água (Online), São Paulo, v. 32, n. 1, p. 175-193, jan.-abril 2019

pois dizer que o verbo "implica sempre uma asserção ou predicação" é ressaltar o caráter de afirmação do verbo e a distinção entre sujeito e predicado, características que, como apresentamos, Auroux (2009) remete ao campo da lógica. A primeira e a segunda edição da Grammatica portugueza, de Júlio Ribeiro, destarte, contêm conceitos de verbos elaborados a partir de critérios comuns para a tradição filosófica, justamente a que a gramática julgava combater.

Essa mesma constatação pode ser feita a partir da análise dos demais conceitos de verbo selecionados. Na gramática de João Ribeiro (1920 [1887])4 observamos o uso do critério funcional-lógico (c3) como principal traço distintivo: a noção de cópula entre o sujeito e um estado ou uma qualidade é sintetizada na palavra "attribuida", assim como pelas "relações de estado ou acção", o que remete claramente à noção de verbo substantivo.

Verbo é a palavra pela qual pode uma acção, um estado ou uma qualidade ser attribuida a um ser. Este ser é o sujeito do verbo. As relações de estado ou acção devem ser naturalmente numerosas, e o seu conjunto constitue a conjugação. (RIBEIRO, 1920 [1887], p. 29).

O conceito de verbo da gramática de Eduardo Carlos Pereira (1907) envereda-se pelo mesmo caminho: "216. Verbo é a palavra que exprime a acção attribuida, sob as relações de tempo e de modo, a uma pessoa ou cousa, como: - O homem anda, andou, andará, andaria - A arvore cahiu, cahirá, cahiria.” (PEREIRA, 1907, p. 88). Constatamos a noção de atribuição do verbo em "acção attribuida", trecho que releva o uso do critério funcional-lógico (c1) para definição de verbo, mesmo que, em sua definição, não apareçam estado ou qualidade: o verbo apenas liga uma ação a uma pessoa ou a uma coisa.

Existe, contudo, uma diferença entre os conceitos de Pereira (1907) e João Ribeiro (1920 [1887]). Para o conceito deste gramático o verbo apenas atribui, enquanto para o de Pereira (1907) o verbo exprimi a atribuição. Ou seja, enquanto no conceito de João Ribeiro (1920 [1887]) o critério é apenas o funcional-lógico (c1),

4 Utilizamos a $19^{a}$ edição por não conseguirmos acesso à primeira.

PRETE, M. Influência da gramática filosófica no conceito de verbo em gramáticas brasileiras Todo conteúdo da Linha D'Água está sob Licença Creative Commons Attribution-NonCommercial 4.0 International License 
Linha D'Água (Online), São Paulo, v. 32, n. 1, p. 175-193, jan.-abril 2019

em Pereira (1907) o uso do critério semântico-semiológico (b3) também ocorre, pois a função do signo é mencionada.

Nosso último conceito analisado é o presente na gramática de Maximino Maciel (1914). Neste conceito, o critério semântico-semiológico (b3) é mais evidente que nos demais, na medida em que deixa clara a distinção pela finalidade do verbo: "serve para affirmar e exprimir": "Verbo é uma palavra de tempo que serve para afirmar e exprimir simultaneamente um facto.” (MACIEL, 1914, p. 128). O conceito de Maciel (1914) segue, portanto, a mesma linha dos demais: ainda que essas gramáticas marquem uma mudança de transição na gramaticografia brasileira, seus conceitos de verbo se alicerçam em critérios típicos da tradição que abnegam.

A tabela a seguir resume a distribuição dos critérios (b3) e (c1) nos conceitos de verbos analisados nas gramáticas publicadas entre o final do século XIX e o início do XX.

Tabela 2: Critérios distintivos em gramáticas publicadas entre o final do século XIX e início do século XX

\begin{tabular}{ccc} 
GRAMÁTICAS & \multicolumn{2}{c}{ CRITÉRIOS DE DISTINÇÃO } \\
Grammatica portugueza, de Júlio Ribeiro (1881) & B3 & C1 \\
Grammatica portugueza, de Júlio Ribeiro (1885) & + & + \\
Grammatica portugueza: curso superior, de João Ribeiro (1887) & + & + \\
Grammatica expositiva, de Eduardo Carlos Pereira (1907) & + & + \\
Grammatica descriptiva, de Maximino Maciel (1914) & + & -
\end{tabular}

As gramáticas que selecionamos como amostra para representar o final do século XX e o início do século XXI, por sua vez, apresentam conceitos que aparentam ser consideravelmente diferentes dos que analisamos até o momento, pois uma nomenclatura particular se destaca, principalmente a que remete às áreas da linguística. No conceito presente na Gramática do português brasileiro, de Perini (2010), por exemplo, notamos essa particularidade:

5 Seria possível, nos conceitos analisados, averiguar ainda vestígios de outras tradições, como a da gramática latina, mas essa tarefa foge ao escopo deste estudo.

PRETE, M. Influência da gramática filosófica no conceito de verbo em gramáticas brasileiras

Todo conteúdo da Linha D'Água está sob Licença Creative Commons Attribution-NonCommercial 4.0 International License 
Linha D'Água (Online), São Paulo, v. 32, n. 1, p. 175-193, jan.-abril 2019

De todas as classes de palavras, o verbo é certamente o mais fácil de reconhecer,
por seus sufixos característicos (andamos, andam, andava, andasse) e pela relação
como outros membros do seu lexema. Com efeito, o lexema verbal é, de longe, o
mais rico da língua, e apresenta características muito peculiares: são palavras que
se opõem em tempo, modo, pessoa e número. (PERINE, 2010, 307, grifo nosso).

Percebemos nesse conceito o uso do termo "lexema", termo que remete "a unidade de base do léxico, numa oposição léxico/vocabulário, em que o léxico é colocado em relação com a língua e o vocabulário da fala" (DUBOIS et al., 1993, p. 360). Suspeitamos que seja esse tipo de terminologia, incomum na gramaticografia tradicional, que desencadeia um falso problema: o de que os conceitos de verbo dessas gramáticas redigidas no início do século XXI sejam completamente inovadores, a ponto de não podermos perceber neles vestígios de tradições gramaticais anteriores, como a da gramática filosófica.

Esse falso problema torna-se evidente, quando analisamos os conceitos dessas gramáticas. O conceito de verbo da Gramática de usos do português, de Neves (2000 [1999]) $)^{6}$, é bastante sintético. A autora define verbo por meio do uso tímido do critério funcional-lógico (c1), que pode ser percebido na menção a predicado - e, por consequência, à oposição entre sujeito e predicado - e o papel que o verbo exerce em sua constituição: "Os verbos, em geral, constituem os predicados das orações.” (NEVES, 2000 [1999], p. 25).

Esse, no entanto, não é o único conceito de verbo que pode ser identificado em Neves (1999). Na sequência, após expor o que chama de "natureza dos verbos", seção onde se encontra essa primeira definição, a autora abre outra para tratar das "subclassificações dos verbos que constituem predicados". Nessa seção, encontramos outras duas definições: I - "Os verbos exprimem uma ação ou atividade." e II - "Os verbos envolvem uma relação entre um nome e um estado..." (NEVES, 2000 [1999], p. 26). No conceito I, percebemos que Neves (2000 [1999]) utiliza o caráter semântico-semiológico (b3), enquanto, no conceito II, ocorre o uso do critério funcional-lógico (c1) para distinção de verbo.

6 Utilizamos a quarta impressão da primeira edição, publicada em 2000. A primeira edição é de 1999.

PRETE, M. Influência da gramática filosófica no conceito de verbo em gramáticas brasileiras 
Linha D'Água (Online), São Paulo, v. 32, n. 1, p. 175-193, jan.-abril 2019

Somente um conceito de Neves (2000 [1999]) - "Os verbos não-dinâmicos são acompanhados por um sintagma nominal (sujeito) que é suporte do estado" (NEVES, 2000 [1999], p. 26) - não é elaborado pela autora por meio de critérios que remetem à tradição da gramática filosófica. Se considerarmos, todavia, que esse último conceito remete mais à ideia de "verbos não-dinâmicos", uma categoria usada pela autora para se referir ao que costumamos chamar de "verbo de ligação", temos uma definição genérica de verbo que remete evidentemente aos critérios utilizados pela tradição da gramática filosófica, conforme nossa sintetização a seguir: "Os verbos, em geral, constituem os predicados das orações. / envolvem uma relação entre um nome e um estado / exprimem uma ação ou atividade."

Castilho (2010), em sua Gramática do português brasileiro, apresenta um procedimento semelhante ao de Neves (1999). A primeira definição que apresenta ao leitor é a definição de sintagma verbal: "O sintagma verbal é a construção nucleada pelo verbo" (CASTILHO, 2010, p. 391). Somente na sequência é que passa a tratar do que chama de "estatuto categorial do verbo", no qual "haverá, portanto, definições (i) gramaticais; (ii) semânticas; e (iii) discursivas dessa classe, de que não se excluem definições mistas.", (CASTILHO, 2010, p. 392). Como podemos perceber, Castilho (2010) explicita os critérios que utiliza para elaboração do conceito categorial do verbo, ou seja, do conceito da classe gramatical verbo.

$\mathrm{Na}$ parte dedicada às propriedades semânticas do verbo, encontramos o critério semântico-semiológico (b3): "Do ponto de vista semântico, os verbos expressam os estados de coisas, entendendo-se por isso as ações, os estados e os eventos de que precisamos quando falamos ou escrevemos." (CASTILHO, 2010, p. 396). E, logo na sequência, onde discorre sobre a "sintaxe do verbo", o critério funcionallógico (c1): "O verbo e seus argumentos constituem o predicado..." (CASTILHO, 2010, p. 396). Notamos que Castilho (2010) recorre tanto à função do signo, quando diz que o verbo é responsável por expressar o estado de coitas, quanto à dicotomia entre sujeito e predicado, ao atribuir ao verbo o papel de compor o predicado.

Não encontramos os critérios que temos analisados somente na Gramática do português brasileiro, de Perini (2010). Seu conceito, que já expusemos, pautase, sobretudo, no critério morfológico, cuja propriedade é identificar o fenômeno linguístico por meio de sua estrutura, fato que o aproxima mais da tradição latina:

PRETE, M. Influência da gramática filosófica no conceito de verbo em gramáticas brasileiras Todo conteúdo da Linha D'Água está sob Licença Creative Commons Attribution-NonCommercial 4.0 International License 
Linha D'Água (Online), São Paulo, v. 32, n. 1, p. 175-193, jan.-abril 2019

"De todas as classes de palavras, o verbo é certamente o mais fácil de reconhecer -, por seus sufixos característicos (andamos, andam, andava, andasse [...] apresenta características muito peculiares: são palavras que se opõem em tempo, modo, pessoa e número." (PERINE, 2010, 307). Não acreditamos que no trecho "pela relação como outros membros do seu lexema." (PERINE, 2010,307) possamos identificar o critério lógico-funcional (c3), ainda que o autor faça menção à ideia de relação. Trata-se, portanto, de um conceito muito mais próximo da tradição latina.

A tabela a seguir resume a distribuição dos critérios $^{7}$ utilizados nos conceitos de verbos analisados nas gramáticas publicadas entre o final do século XX e o início do XXI.

Tabela 3: Critérios distintivos em gramáticas publicadas entre o final do século XX e o início do século XXI

\begin{tabular}{ccc} 
GRAMÁTICAS & \multicolumn{3}{c}{ CRITÉRIOS DE DISTINÇÃO } \\
Gramática de usos do português, de Neves (1999) & B3 & C1 \\
Gramática do português brasileiro, de Perini (2010) & + & + \\
Gramática do português brasileiro, de Castilho (2010) & - & - \\
\hline
\end{tabular}

\section{Conclusão}

A análise dos critérios utilizados pelos autores das gramáticas em seus conceitos de verbo nos permite afirmar que o critério semântico-semiológico (b3) e o funcional-lógico (c1) - característicos da tradição da gramática filosófica - são utilizados em praticamente todas as obras que compõem nosso corpus, fato que confirma nossa hipótese inicial ao relativizar a ideia de que essa tradição seja superada pelas gramáticas publicadas na transição do século XIX para o XX, e irrelevante nas publicadas na transição do século XX para o XXI. Vestígios da gramática filosófica não foram constatados apenas no conceito de verbo da Gramática do português

7 Seria possível, nos conceitos analisados, averiguar ainda vestígios de outras tradições, como a da gramática latina, mas essa tarefa foge ao escopo deste estudo.

PRETE, M. Influência da gramática filosófica no conceito de verbo em gramáticas brasileiras 
Linha D'Água (Online), São Paulo, v. 32, n. 1, p. 175-193, jan.-abril 2019

brasileiro, de Perini (2010), visto que seu conceito de verbo se pauta em um critério mais próximo da tradição da gramática latina: o critério morfológico (a).

Alguns estudos recentes, como os de Polachini (2012, 2015b e 2018), chegaram a resultados semelhantes aos nossos ao analisar gramáticas publicadas no final do século XIX e início do século XX. Nesses estudos, a autora constata que terminologia característica da tradição da gramática filosófica (como o uso da noção de verbo impessoal ou de verbo substantivo, por exemplo) ainda está presente em gramáticas desse período, embora seu uso diminua aos poucos, até definitivamente desaparecer, o que marcaria rupturas substanciais. Essas rupturas substanciais, embora sejam identificadas no escopo das análises de Polachini (2012), por exemplo, podem, numa perspectiva lato, não existir, pois, como comprovamos nos conceitos de verbos analisados, a tradição da gramática filosófica é a base para a elaboração do conceito de verbo e permanece presente até os tempos atuais, em gramáticas publicadas recentemente, já no século XXI.

Por essa razão, defendemos a ideia de que tradições dificilmente podem se tornar superadas em algum momento da história, visto que a concepção do objeto técnico gramática - e suas reformulações - pressupõe o conhecimento acumulado na longa duração do tempo. Conforme preceitua Auroux (2006) e Leite (2017), as gramáticas, como objetos técnicos que são, podem sofrer alterações, reformulações, mas, ao longo do tempo, revelam certa estabilidade que possibilitam que sejam reconhecidas como uma gramática. Entendemos que essa mesma linha de raciocínio pode ser utilizada para suas partes, como o conceito de verbo. $\mathrm{O}$ conhecimento acumulado, portanto, nunca é totalmente desprezado, tampouco definitivamente superado. As rodas da locomotiva sempre estarão presentes.

\section{Referências}

AUROUX, S. La grammaire générale et les fondements philosophiques des classements de mots. In: Langages, 23e année, n. 92, 1988. Les parties du discours. pp. 79-92.

Les modes d'historicisation. In: Histoire Épistémologie Langage, tome 28, fascicule 1, 2006. Histoire des idées linguistiques et horizons de rétrospection. pp. 105-116.

PRETE, M. Influência da gramática filosófica no conceito de verbo em gramáticas brasileiras 
Linha D'Água (Online), São Paulo, v. 32, n. 1, p. 175-193, jan.-abril 2019

A revolução tecnológica da gramatização. Campinas: Editora da Unicamp, 2009.

CÂMARA, M. Estudos de português no Brasil. In: UCHÔA, C.E.F. Dispersos. Rio de Janeiro: Editora Lucerna, 2004.

CASSEB-GALVÃO, V. C.; NEVES, M. H. M. (Org.). Gramáticas contemporâneas do português: com a palavra, os autores. São Paulo: Parábola Editorial, 2014.

CASTILHO, A. Nova gramática do Português brasileiro. São Paulo: Contexto 2010.

CAVALIERE, R. A gramática no Brasil: ideias, percursos e parâmetros. Rio de Janeiro: Lexikon, 2014.

Uma proposta de periodização dos estudos linguísticos no Brasil. Alfa, São Paulo, 45: 49-69, 2001.

COLOMBAT, B. FOURNIER, J.M. PUECH, C. Uma história das ideias linguísticas. São Paulo: Contexto, 2017.

ELIA, S. Estudos filológicos no Brasil. In: ELIA, S. Ensaios de filologia. Rio de Janeiro: Livraria Acadêmica, 1963.

FAVERO, L. L. As concepçôes linguísticas no século XVIII: a gramática portuguesa. Campinas: Editora da UNICAMP, 1996.

; MOLINA, M. As concepçôes linguísticas no século XIX: a gramática no Brasil. Rio de Janeiro: Lucerna, 2006.

LEITE, M. Q. Tradição, invenção e inovação em gramáticas da língua portuguesa: séculos XX e XXI. In: CASSEB-GALVÃO, V. C. \& NEVES, M. H. M. (Org.). Gramáticas contemporâneas do português: com a palavra, os autores. São Paulo: Parábola Editorial, 2014.

MACIEL, M. Grammatica descriptiva. 5. ed. Rio de Janeiro: Francismo Alves \& Co., 1914.

MOTA, N. A; CERQUEIRA, I. B; DE AZEVEDO, I. C. M. Gramatização do português brasileiro nos séculos XIX e XX e início do século XXI. Entrepalavras, Fortaleza, v. 7, p. 552-567, ago./dez. 2017.

PRETE, M. Influência da gramática filosófica no conceito de verbo em gramáticas brasileiras Todo conteúdo da Linha D'Água está sob Licença Creative Commons Attribution-NonCommercial 4.0 International License 
Linha D'Água (Online), São Paulo, v. 32, n. 1, p. 175-193, jan.-abril 2019

NASCENTES, A. A filologia portuguesa no Brasil (1939). In: NETO, R.B. (Org.) Estudos filológicos: volume dedicado à memória de Antenor Nascentes. Rio de Janeiro: Academia Brasileira de Letras, 2003, p. 186-204.

NEVES, M. H. M. Gramática de usos do português. São Paulo: Editora UNESP, 2000.

PARREIRA, A. Contribución a la historia de la gramática brasileña del siglo XIX. 2011, 488p. Tese (Doutorado) - Faculdade de Filología, Universidad de Salamanca, Salamanca, 2011.

PEREIRA, E. C. Grammatica expositiva. São Paulo: Weeiszflog Irmãos \& Co., 1907.

PERINE, M. Gramática do português brasileiro. São Paulo: Parábola Editorial, 2010.

POLACHINI, B. Considerações sobre o impacto da Grammaire Générale et Raisonnée de Port-Royal (1660) no tratamento da sintaxe de gramáticas brasileiras do português do século XIX. Confluência, n. 39-40, p. 296-314, 2012.

Uma proposta de periodização "complexa" para gramaticografia oitocentista do português. In: POLACHINI, B; CRUDIS, J; BORGES, P; DANNA, S. M. (Org.). Cadernos de bistoriografia linguistica do CEDOCH. São Paulo: FFCLH/USP, 2015a.

. Verbos impessoais e unipessoais em gramáticas brasileiras oitocentistas do português. Revista Argentina de Historiografia Linguistica, v. 7, p. 55-67, 2015b.

Uma história serial e conceitual da gramática brasileiras oitocentista de língua portuguesa. Tese (Doutorado em Linguística) - Universidade Estadual de São Paulo, São Paulo, 2018.

RANGEL, V. L. S. Gramatização do português brasileiro no século XXI: uma língua trans(nacional). Anais do II Seminário Interno de Pesquisas do Laboratório Arquivos do Sujeito, UFF, Niterói, 2, p. 169-178, 2013.

RIBEIRO, J. Grammatica portugueza. 2. ed. São Paulo: Teixeira \& Irmãos, Editores, 1885. . Grammatica portugueza. São Paulo: Typ. de Jorge Seckler, 1881.

. Grammatica portugueza: curso superior. 19. ed. Rio de Janeiro: Livraria Classica de Alves, 1889.

PRETE, M. Influência da gramática filosófica no conceito de verbo em gramáticas brasileiras Todo conteúdo da Linha D’Água está sob Licença Creative Commons Attribution-NonCommercial 4.0 International License 
Linha D'Água (Online), São Paulo, v. 32, n. 1, p. 175-193, jan.-abril 2019

SOARES, J. B. Grammatica philosofica da lingua portugueza. 5. ed. Lisboa: Typographia da Academia Real das Sciencias. 1871.

VIDAL NETO, J. B. C. A 'Grammatica portugueza, de Júlio Ribeiro: um corte epistemológico na gramaticografia brasileira e a questão da língua portuguesa no Brasil. Tese de mestrado. FFLCH/USP, São Paulo, 2010.

Recebido: 13/02/2019.

Aprovado: 06/04/2019.

PRETE, M. Influência da gramática filosófica no conceito de verbo em gramáticas brasileiras 